doi:10.1038/nature04952

\title{
Induction of DNA methylation and gene silencing by short interfering RNAs in human cells
}

Hiroaki Kawasaki \& Kazunari Taira

Nature 431, 211-217 (2004); corrigendum Nature 431, 878 (2004)

There are several independent papers ${ }^{1-3}$ supporting the existence of siRNA-mediated suppression of transcription associated with histone methylation and DNA methylation in mammalian cells with targeting of a promoter region, as we described in this Letter. Unfortunately, however, a proper data notebook is not available as evidence to support our findings, which constitutes non-adherence to ethical standards in scientific research. In accordance with the recommendations from the National Institute of Advanced Industrial Science and Technology, K.T. therefore wishes to retract this paper.

H.K. maintains that all the data contained in this Letter are valid and so declines to be a co-signatory of this retraction.

1. Morris, K. V., Chan, S. W., Jacobsen, S. E. \& Looney, D. J. Small interfering RNA-induced transcriptional gene silencing in human cells. Science 305 , 1289-1292 (2004)

2. Castanotto, D. et al. Short hairpin RNA-directed cytosine $(\mathrm{CpG})$ methylation of the RASSF1A gene promoter in HeLa cells. Mol. Ther. 12, 179-183 (2005).

3. Suzuki, K. et al. Prolonged transcriptional silencing and CpG methylation induced by siRNAs targeted to the HIV-1 promoter region. J. RNAi Gene Silencing 1, 66-78 (2005) 